\title{
Why carers matter
}

Helen Cowan's husband is quadriplegic and she helps care for him at home. Here, she describes the importance of health professionals recognising the part played by carers

\author{
Helen Cowan
}

When my husband is admitted to hospital you might assume that I can take a step back from being his carer, but the reverse is true. Although my husband is usually an independent and professionally successful man, when sick he becomes tired, confused, and vulnerable. Because he is bed bound I become his arms and legs, helping him to turn and reposition, wash and dress, and get his food and drink. Crucially, I become his eyes, monitoring his body for signs of pressure damage. I also become his motivator and mood monitor: depression and anxiety are never far away when disability suddenly looms larger than in normal life.

\section{Carers are not just visitors}

During one admission, I stayed at my husband's bedside for 48 hours. Much as I would have liked to hand over his care to staff, I knew that this would be difficult because of his specific needs.

Helping patients to turn, wash, dress, eat, and drink are basic skills, but it can take a while to learn how best to meet particular needs. At home a team of two or three carers and myself have learnt how to position my husband prone with a subluxated right hip; we know where to place the four body pillows to relieve pressure.

I know the triggers, signs, and treatment for autonomic dysreflexia - a spike in blood pressure - it can be triggered by something as simple as a full bladder or bowel distension. Health professionals are generally not taught about this condition, and my husband and I have seen it misdiagnosed.

Carers possess a knowledge that cannot be gleaned in a single handover. And mistakes matter: a tiny pressure sore can have devastating consequences.

\section{See us as a team}

The hospital system doesn't always understand and support the relationship between patients and carers. For example, I spent an uncomfortable night in hospital in a chair; and another on a mattress (that $I$ had to request) on the floor of a bay with three other male patients besides my husband, and yet empty side rooms could have accommodated my husband and I together. Parents are accepted during a child's admission, so why not the carers of adult patients? With no bed provided I felt like an inconvenience.

I didn't like to leave my husband in case a ward round happened or he needed my help. Food and drink were scarce and expensive. Could carers purchase food at staff prices? Might the tea trolley include drinks for carers as well as for patients? Could carers be given notice of ward rounds?

What I found particularly stressful was the feeling that I had no right to be in hospital. I worried that staff would be annoyed at my presence. A warmer welcome and understanding from staff would have worked wonders; asking how they could best work with my husband and I would have transformed our stay. Doctors can play a helpful role here. They might start the conversation with the patient and carer, perhaps by asking how both are coping. They could work with the patient and carer to understand how medical problems are dealt with at home. Doctors can help by deciding when best to prescribe drugs to fit in with physical limitation-for example, drips being more easily administered when the patient is not prone; they can also work out ways to help patients and carers get home more quickly to their familiar, adapted environment.

\section{A partner ready to listen and lead}

Most of all, I wanted to be seen as an expert partner in care; someone who is prepared to listen and lead. When inpatient teams have worked with me we have achieved a good understanding of the needs of both myself and my husband. After consultation, the medical team expedited discharge, planned a home drip, and called me back to collect antibiotics after my husband had a positive swab result. These things were helpful and made my husband and I feel more in control.

Experience has been our teacher and we have learnt what works. When it comes to caring for patients with disabilities, everyone benefits when carers are seen as partners in care. 


\section{What you need to know}

- Carers are experts in patients' needs

- Welcoming carers and patients onto the ward means thinking about where carers will sleep and when they will be able to eat or take a break

- By treating patient and their carers as a team, everyone benefits

\section{Education into practice}

- Are carers viewed as expert partners in care where you work? Do you communicate with them (with consent)?

- Do you consider how patients with disabilities can best tackle their physical needs while also dealing with their medical needs?

- Is there anything you will consider doing differently as a result of reading this article?
Competing interests: I have read and understood BMJ policy on declaration of interests and declare the following: None.

Patient consent obtained.

Provenance: Not commissioned; not externally peer reviewed.

Published by the BMJ Publishing Group Limited. For permission to use (where not already granted under a licence) please go to http://group.bmj.com/group/rights-licensing/ permissions 